\title{
Assessing Action Situation Networks: A Configurational Perspective on Water and Energy Governance in Irrigation Systems
}

\author{
Christian Kimmich ${ }^{*,+}, \S$ and Sergio Villamayor Tomas*,‡ \\ *Environmental and Resource Economics \\ Swiss Federal Research Institute \\ WSL Zürcherstrasse 111, 8903 Birmensdorf (ZH), Switzerland \\ †Faculty of Social Studies, Masaryk University \\ Joštova 10, 61500 Brno, Czech Republic \\ ${ }^{\ddagger}$ Institut de Ciència i Tecnologia Ambientals \\ Universitat Autònoma de Barcelona \\ 08193 Barcelona, Spain \\ §christian.kimmich@gmail.com \\ Received 31 January 2017 \\ Revised 9 April 2017 \\ Accepted 12 December 2017 \\ Published 18 January 2018
}

\begin{abstract}
The action situation is a core component of actor-centered institutional analysis of natural resource governance. Institutional analysis frameworks have been extended to observe multiple situations structured into networks. If further operationalized, this extension can improve policy diagnosis of human-environmental interactions. This paper proposes two complementary ways to move in that direction. First, we propose the use of qualitative configurational analysis and game theory to study the interactions between situations and assess the contribution of each to a desired outcome. Second, we draw on centrality measures to assess the benefits and risks of implementing policies that aim to change the equilibria in action situations. Both analytical strategies are applied to two cases involving irrigation and energy governance. In the Spanish case, centrality of the water allocation situation justifies a configuration of drought measures that also tackle cooperation in monitoring and infrastructure maintenance. In the Indian case, groundwater governance and adequate infrastructure capacity provision are necessary preconditions to enable coordinated technology adoption, which facilitates incentives for regulated irrigation. In both the cases, some action situations' positive outcomes are necessary in every configuration to guarantee optimal equilibria in the network. In the context of energy-fed
\end{abstract}

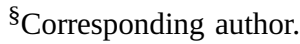


irrigation systems, the proposed analytical strategies permit integrating interactions between water use, energy use and food production decisions in policy diagnoses. The analysis can be extended to identify archetypes, network closure, as well as structural and functional connectivity of networks in social-ecological systems.

Keywords: Network analysis; configurational analysis; institutional analysis and development framework; water-energy-food nexus; social-ecological system; Spain; India.

\section{Introduction}

The action situation (AS) is a core component of actor-centered institutional frameworks interested in the study of common pool resource governance (Anderies et al. 2004; Hagedorn 2008; Kiser and Ostrom 2000; Pahl-Wostl et al. 2010). The concept refers to the interdependent decisions that different actors or groups can make and the joint outcomes that result from those decisions. An AS comprises a set of interacting actors or groups, their positions or roles, choices, information, and the outcomes attached to their choices. The situations can be both physically and institutionally shaped. The core of an AS is frequently modeled as a game and can involve dilemmas, conflicts, or coordination problems; entail operational, collective, and constitutional choices (Kiser and Ostrom 2000; Ostrom et al. 1993); and incorporate social-ecological and technical system properties (Anderies et al. 2004). Frequently, multiple situations jointly affect natural resource governance forming networks of ASs (Lubell 2013; McGinnis 2011). In this context, ASs can be associated to different governance functions, or to different levels of decision making, scale, and polycentricity (Blomquist and Schlager 2005; Kiser and Ostrom 2000; Meyer and Thiel 2012; Moss 2004; Pahl-Wostl et al. 2010).

Recent works have looked at natural resource governance from an AS network perspective (Kashwan 12015; Kimmich 2013a; McGinnis 2011), but without explicitly taking into account network structure. This paper contributes to filling that gap. The paper addresses the following questions: How can we meaningfully transfer network analysis concepts for analytical purposes in AS networks? How do linked ASs influence each other? What is the scope for inducing change across situations in a network to change outcomes of interest? Given particular policy problems or objectives, how can we distinguish analytically relevant from irrelevant situations? To address these questions, the paper uses centrality measures and configurational analysis and adapts them to the study of linked ASs.

To test the usefulness of centrality and configurational analysis in AS networks, we conduct a qualitative analysis of two local irrigation governance cases. We contrast a successful case of drought-resistant irrigation with a failing case of energy and ground water overuse. The selection of irrigation cases was based on several reasons. First, much of the pioneering work on AS analysis was carried out 
in the context of community-based irrigation governance (Ostrom et al. 1993). Second, irrigation systems have a relatively straightforward function - i.e., distributing water to users in the right amount and at the right time. Accordingly, it was relatively easier than in other, more multifunctional systems, to identify relevant outcomes and the network of involved situations and actors.

According to the analysis, centrality can be especially informative with regard to the opportunities and risks of policy action. The configurational method, in turn, helps to trace the mechanisms, through which desired outcomes can be realized. Important caveats for further work are related to the definition of the boundaries of the AS networks and the agency of actors to influence outcomes across situations.

Section 2 introduces the analytical framework. Section 3 describes the findings concerning centrality and configurations in the two AS network cases. Section 4 discusses the key insights from these results, implications for generalization, limitations, and potential paths to build on this analysis. Section 5 concludes.

\section{AS Network Analysis: Building Concepts for Diagnosis}

\subsection{Action situation networks}

The analysis of networks of ASs has gained notable interest in recent years (Lubell 2013; McGinnis 2011; Pahl-Wostl et al. 2010; Schlüter et al. 2010; Sendzimir et al. 2010; Siddiki et al. 2011). According to actor-centered network approaches, ASs are directly linked or adjacent (McGinnis 2011, p. 53) if the outcome of one situation directly influences the structure or actors in another situation. The idea of focal ASs refers to the AS whose outcomes are the main phenomenon under study. In the resource governance context, ASs can be associated with functions, including production, provision, financing, consumption, coordination, dispute resolution, rulemaking, and monitoring (McGinnis 2011). Each of these functions can involve the actions of multiple actors. Also, the number and type of actors involved in one situation can differ significantly from those in linked situations, and the game type can differ from one AS to the other.

Four types of links across AS can be distinguished (Kimmich 2013a): the biophysical transactions, information, institutions, and actors involved in both situations. A one-mode network would only consider linkages between actors. A two-mode or bipartite network includes linkages between actors and venues (Lubell et al. 2014). As shown in Fig. 1, one can envision a two-mode network in which three actors $A_{n}$ interact in game $\boldsymbol{\Gamma}_{1}$ and the same actors interact with a different actor B in a different event/game/situation $\boldsymbol{\Gamma}_{2}$. Figure 1 is an example of an actor linkage, whereby the actors $A_{n}$ not only represent nodes but also the link between the two games. The two games could also be directly linked, if, for 


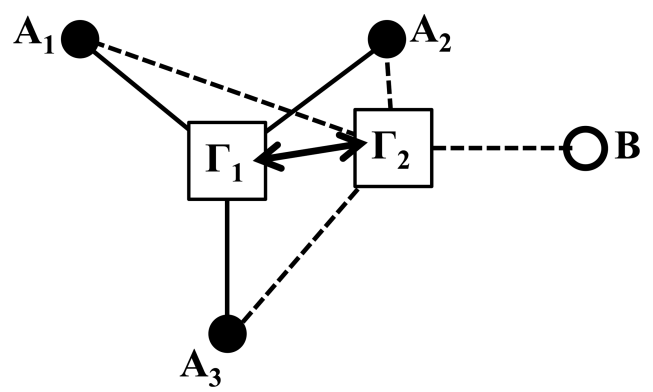

Figure 1. A Two-Mode Graph of Actors $\left(A_{n} ; B\right)$ and Events (i.e., Games $\left.\Gamma_{i}\right)$ Actors are Involved in.

example, the collective outcome of $\boldsymbol{\Gamma}_{1}$ is an institution, transaction, or information that is changing the payoff structure in $\boldsymbol{\Gamma}_{2}$. AS can, thus, also directly influence each other by changing the payoffs, the set of available choices, or the number and type of actors involved. This results in a more complex network that most closely resembles the characteristics of AS networks.

\subsection{Centrality}

Despite the increasing interest in AS networks, few authors have looked at how different structural properties of these networks affect outcomes. Social network analysis (SNA) has been particularly prolific in that regard. Centrality is one of the most well-studied and frequently used properties in SNA. There are different measures of centrality such as degree, closeness, betweenness, harmonic closeness, or eigenvector centrality (Costenbader and Valente 2003). The most intuitive and popular among them is degree centrality, which counts the number of ties that an actor has (Freeman 1978; Scott 2012). Everett and Borgatti (2005) extend the concept of centrality to characterize groups of actors within networks, as well as to two-mode networks of actors and events. This opens up possibilities to understand relationships in networks in which not only actors but also ASs in the form of forums, associations, or events are in play (Lubell et al. 2014).

Centrality and the associated indicator of degree are here proposed to feature ASs. This can provide a first insight at the relevance they play within a given network as well as explore whether network structure can make a difference in the diagnosis of resource governance. We can think of types of centrality based on four types of linkages: actor-, information-, institutional, and physically driven centrality. Although each type focuses on different links, all of them inform the possibility that a particular output of the AS has an influence over, or is influenced by, the output of other ASs. Thus, one straightforward way of operationalizing centrality is identifying whether an AS has any relevant linkage (i.e., a linkage with 
an influence on outputs) with other situations, mediated through actors, institutional constraints, information flows, or physical transactions.

\subsection{Configurations of insufficient but necessary conditions}

To assess the relevance of different ASs of a network, we propose a configurational approach. The configurational approach to causality has been put forward as a strategy for systematic comparative analysis, where cases are understood as a combination of factors, or conditions, that produce a given outcome of interest (Rihoux and Ragin 2009). Configurational analysis takes into account that parts, in our case ASs, can only be explained by considering the network, in which they are embedded. Configurational approaches have been used in comparative analyses (Ragin 1989), in organizational studies (Meyer et al. 1993), and have recently also been applied in multifunctional agriculture (Hassink et al. 2012), institutional analyses of irrigation governance (Hamidov et al. 2015), adaptation to climate change (Roggero 2015), and in identifying archetypes of large-scale land acquisitions (Oberlack et al. 2016).

One question that is usually addressed in configurational analyses is whether different sets of conditions are necessary and also sufficient to produce an outcome. A condition is necessary for an outcome if it is always present when the outcome occurs. A condition or configuration of conditions is sufficient for an outcome if the outcome always occurs under that condition or configuration. It is usually the case that a condition is not necessary or sufficient by its own to produce an outcome. Rather, outcomes are the result of INUS conditions, i.e., insufficient but necessary parts of a configuration which is itself unnecessary but sufficient (Ragin 1989). This justifies an interest in identifying configurations of conditions rather than conditions alone.

\subsection{Equilibrium conditions in AS networks}

In this paper, we propose looking at the configurations of ASs that lead to equilibria in a network. ASs can be modeled as games. From a game-theoretic perspective, a situation is in equilibrium when no actor has an incentive to individually deviate from a status quo (Bowles 2004). By analogy, in an AS network, an equilibrium exists when no actor has an incentive to individually deviate in any of the situations, i.e., all situations are in equilibrium. As formalized by economic network analysis (ENA) scholars, the structure of a network and the properties of its interdependencies determine the related feasible equilibrium outcomes, switching costs, and thresholds (Farrell and Klemperer 2007; Galeotti et al. 2010). The likelihood of equilibrium shifts in a network of ASs can be 
partially informed by the type of game that actors play in each of the situations of the network. Two major categories of games considered by ENA scholars are games of coordination, such as the assurance problem, and games of conflict, such as the prisoner's dilemma. In the one-shot prisoner's dilemma, defection is the dominant strategy, which usually leads to a suboptimal equilibrium outcome, while in coordination problems, both suboptimal and optimal equilibria exist and can be stable. In the prisoner's dilemma, the socially optimal solution is potentially hindered by free-riding behavior, which is not the case in coordination problems (see e.g., Bowles 2004). In coordination problems, it is socially and also individually optimal to cooperate if the other does as well. Interests are aligned. There are no gains from free riding, but a risk of losses through coordination failures if the involved actors take different decisions. A key example is the AS of technology adoption that will be explained later (see Sec. 3.1.2). All being equal, suboptimal

Table 1. Set Values of Selected* Configurations and their Impact on the Focal AS ( $\left.\mathrm{AS}_{\text {wal }}\right)$ in the Spanish Case

\begin{tabular}{lcccccc}
\hline & $\mathrm{AS}_{\text {wal }}$ & $\mathrm{AS}_{\text {wap }}$ & $\mathrm{AS}_{\mathrm{mnt}}$ & $\mathrm{AS}_{\text {mon }}$ & $\mathrm{AS}_{\text {eal }}$ & $\mathrm{AS}_{\text {einv }}$ \\
\hline $\begin{array}{l}\text { Game type } \\
\begin{array}{l}\text { Centrality* } \\
\text { Pathways }\end{array}\end{array}$ & $\mathrm{CP}$ & $\mathrm{PD}$ & $\mathrm{PD}$ & $\mathrm{PD}$ & $\mathrm{CP}$ & $\mathrm{PD}$ \\
$\begin{array}{l}\text { 1.1. Collective reduction of crop } \\
\quad \text { water needs }\end{array}$ & $1 * *$ & 1 & 1 & 1 & $\mathrm{NR}$ & $\mathrm{NR}$ \\
$\begin{array}{l}\text { 1.2. Attempt to collective reduction } \\
\quad \text { of crop water needs but enforce- }\end{array}$ & 0 & 1 & 1 & 0 & $\mathrm{NR}$ & $\mathrm{NR}$ \\
$\quad$ ment issues & & & & & & \\
$\begin{array}{l}\text { 1.3. Collective reduction of crop } \\
\quad \text { water needs but fee payment }\end{array}$ & 1 & 1 & 0 & 1 & $\mathrm{NR}$ & $\mathrm{NR}$ \\
$\quad$ issues & & & & & & \\
$\begin{array}{l}\text { 2.1. Increase in water use efficiency } \\
\text { 2.2. Increase in water use efficiency }\end{array}$ & 1 & 1 & $\mathrm{NR}$ & $\mathrm{NR}$ & 1 & 1 \\
$\quad$ but rebound effect & 0 & 0 & $\mathrm{NR}$ & $\mathrm{NR}$ & 1 & 1 \\
$\quad$ but electricity price vulnerability & 1 & 1 & $\mathrm{NR}$ & $\mathrm{NR}$ & 0 & 1 \\
\hline
\end{tabular}

Game types: $\mathrm{PD}=$ Prisoner's Dilemma, $\mathrm{CP}=$ Coordination Problem.

*Degree centrality scores are a count of the number of physical, institutional. and actor linkages.

**Outcome in $\mathbf{A S}_{\mathrm{wal}}$ : Efficient water allocation during droughts.

1: The dilemma or coordination problem in the AS is solved.

0 : The dilemma or coordination problem in the AS is not solved.

NR: The AS is not relevant in the current pathway.

Note 1: An AS is not necessary if it is possible to reach a high equilibrium in the focal AS without solving the coordination problem/social dilemma in the AS under question (see, e.g., $\mathbf{A S}_{\text {mon }}$ in 1.2). Note 2: The purpose was not to identify all potentially possible configurations, but rather to systematically compare relevant configurations according to our understanding of the cases. This applies also to Table 2 . 
Table 2. Set Values of Selected Configurations and their Impact on the Focal Action Situation $\left(\mathrm{AS}_{\mathrm{cop}}\right)$ in the Indian Case

\begin{tabular}{lccccccc}
\hline & $\mathrm{AS}_{\text {cop }}$ & $\mathrm{AS}_{\text {pes }}$ & $\mathrm{AS}_{\text {slta }}$ & $\mathrm{AS}_{\text {cut }}$ & $\mathrm{AS}_{\text {col }}$ & $\mathrm{AS}_{\text {cap }}$ & $\mathrm{AS}_{\text {gex }}$ \\
\hline Game type & $\mathrm{CP}$ & $\mathrm{CP}$ & $\mathrm{CP}$ & $\mathrm{PD}$ & $\mathrm{PD}$ & $\mathrm{CP}$ & $\mathrm{PD}$ \\
Centrality & 3 & 1 & 1 & 4 & 2 & 2 & 1 \\
Pathways & & & & & & & \\
1. Coordinated DSM adoption & $1 *$ & 0 & 1 & 1 & 1 & 1 & 0 \\
2. Groundwater governance & 1 & 0 & 1 & $\mathrm{NR}$ & 0 & 0 & 1 \\
3. Self-governed capacity management & 1 & 0 & 1 & 1 & 0 & 0 & 0 \\
4. Pro rata** tariff policy & 1 & 1 & 1 & 1 & 0 & 0 & 0 \\
\hline
\end{tabular}

*Outcome in $\mathbf{A S}_{\text {cop }}$ : Improved power quality and energy efficiency for climate change mitigation and adaptation.

** With pro rata tariffs, electric energy is priced according to the quantities utilized. This does not necessarily imply cost coverage for the energy provided.

1: The dilemma or coordination problem in the AS is solved.

0 : The dilemma or coordination problem in the AS is not solved.

NR: The AS is not relevant in the current pathway.

outcomes are far less likely to change in prisoners' dilemmas than in coordination problems. Conversely, optimal equilibria in games of conflict are less stable to changes in payoff structures than in coordination games. In coordination problems, information about expected behavior of others, for example obtained through communication, is crucial, while information alone cannot solve prisoners' dilemmas.

Following ENA reasoning, the analysis is carried out by first looking at all ASs in the network as they take different states (i.e., solved or unsolved games), and then exploring whether the configurations they form explain equilibrium outcomes in the focal AS. We expect that no AS's outcome is necessary or sufficient by itself to explain focal AS outcomes. Rather, we expect that equilibrium outcomes in some situations are necessary parts of one or multiple configurations that are sufficient to explain those focal outcomes of interest. These are INUS situations and thus relevant for policy analysis. Irrelevant ASs are therefore those that do not make a difference in network equilibria given a particular configuration (see "NR" codes for some of the ASs in Tables 1 and 2).

\section{Configurations in Two Cases of AS Networks}

We use two case studies to test the usefulness of the configurational analysis and centrality measure. The cases were selected from two typical irrigation infrastructures, namely groundwater and surface irrigation structures. We do not intend to compare both cases; rather, we focus on the explanatory value of centrality and the usefulness of the configurational approach for assessing AS networks. 
We sampled a Spanish case and an Indian case, each representing extremes with regard to the outcome of the focal AS: The Spanish case is a case of success, in which a cooperative water allocation equilibrium is stable despite the occurrence of drought shocks. In the Indian case, a persistent low equilibrium keeps energy utilization for irrigation and water use on a highly inefficient trajectory and leaves groundwater overexploited.

In the analysis, we consider only the most salient physical, actor, informational, and institutional links between the AS of each case that explain the relative success/failure of the case (see Figs. 2 and 3). For the configurational analysis, we constructed two tables, one per case (see Tables 1 and 2). Each table includes configurations of different states of the situations that can produce a desired outcome in the focal AS. We did not represent all configurations but only those we understood to be relevant based on existing knowledge of the cases (Kimmich 2013a,b, 2016; Kimmich and Sagebiel 2016; Müller et al. 2016; Villamayor-Tomas 2014). In the Spanish case, the configurations reflect two paths through which

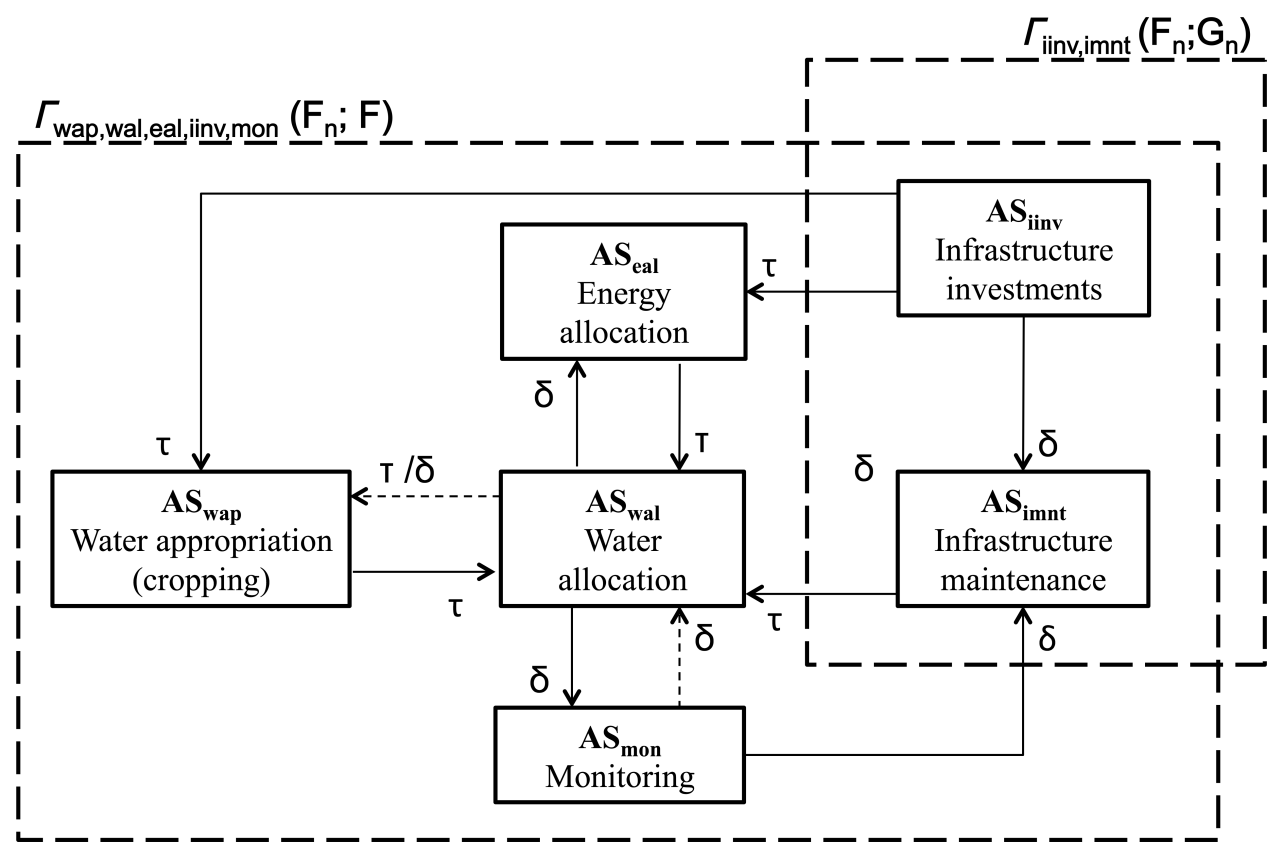

Figure 2. The AS Network in the RAA Case

$\delta$ : institutional linkage; $\tau$ : physical linkage. Dotted arrows: linkages that change from non-drought to drought periods.

Notes: Actor linkages are depicted as dashed boxes around ASs of common actors, including farmers $F$, government $G$, opposition parties $O$, and utility staff $U$. Physical transactions $(\tau)$, and informational $(\iota)$ and institutional $(\delta)$ linkages are depicted as arrows. 


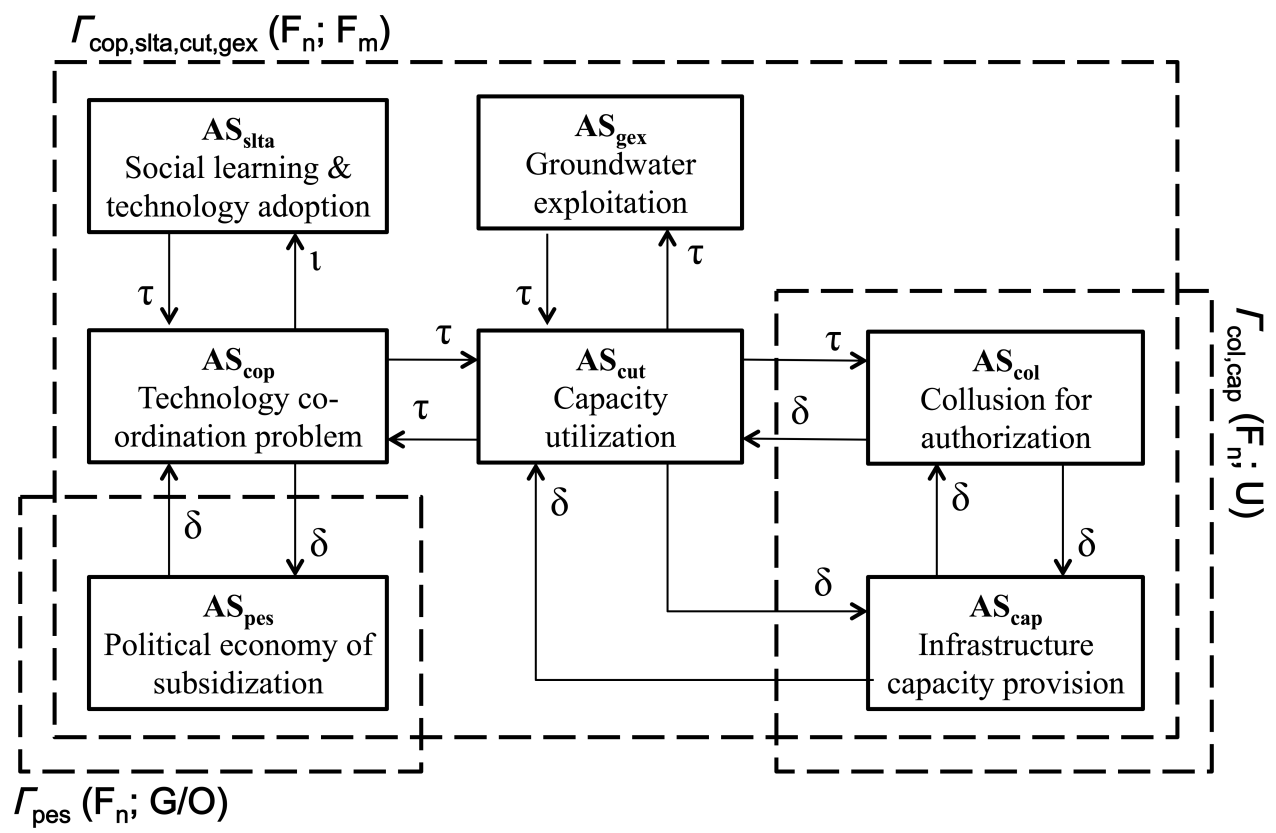

Figure 3. The AS Network in the Indian Case

$\delta$ : institutional linkage; $\tau$ : physical linkage, $\iota$ : information linkage.

Notes: Actor linkages are depicted as dashed boxes around ASs of common actors, including farmers. $F$, government $G$, opposition parties $O$, and utility staff $U$. Physical transactions $(\tau)$, and informational $(\iota)$ and institutional $(\delta)$ linkages are depicted as arrows.

actors have coped with droughts. In the Indian case, the configurations represent currently debated and additional possible ways about how to overcome the overuse of energy and groundwater.

\subsection{Irrigation systems in Spain: How to sustain a high equilibrium}

Spain is well recognized for the long tradition and autonomy of its irrigation associations (Blomqvist et al. 2005; Ostrom et al. 1993), which are rooted in both customary law and a water use right system that grants the associations the authority to manage water use within their jurisdictions. Since the beginning of the 20th century, the Spanish government has actively engaged in the conversion of dry land to irrigated land and the promotion of new irrigation communities as a means of strengthening economic development (Bolea Foradada 1986). Riegos del Alto Aragon (RAA) is one of the oldest and largest state-promoted irrigation projects in the country. It currently encompasses 50 irrigation districts for a total of approximately 126,000 irrigable hectares. 
One key challenge in large irrigation projects is water allocation across farmers (Subramanian et al. 1997). This challenge seems to have been overcome quite satisfactorily in the RAA project, as judged by the increasing production of irrigated crops over time (Villamayor-Tomas 2014).

While droughts in Spain are not a new phenomenon, their governance still constitutes a challenge due to their increasing unpredictability, recurrence, and severity. The irrigation systems in the RAA project, however, seem to cope relatively well with droughts (Villamayor-Tomas 2014). How can we understand the effective allocation of water among farmers in the RAA project under both normal conditions of water availability and drought? How does the network of situations help to explain the performance of the project, and what does this network look like? Can the configurational approach and centrality measures help us to understand the influence of the network of situations on water allocation?

\subsubsection{The AS network and linkages in the RAA}

One of the main functions of irrigation systems and organizations is to guarantee that each user receives sufficient water in a timely manner. Thus, the focal AS is water allocation ( $\mathrm{AS}_{\text {wal }}$ in Fig. 2). In the RAA project, water is allocated by Water User Associations (WUAs) at the system level, and a General Association, and a Water Agency at the project level. WUAs within the project and farmers within each WUA cannot irrigate simultaneously due to infrastructure constraints. Thus, even if there is enough water available, farmers and WUAs need to solve a coordination problem to efficiently allocated water. This is done via an irrigation schedule (e.g., a turns rule). Linked to the focal situation, there are a cropping situation $\left(\mathrm{AS}_{\text {wap }}\right)$, an infrastructure maintenance situation $\left(\mathrm{AS}_{\text {imnt }}\right)$, and a monitoring $\left(\mathrm{AS}_{\mathrm{mon}}\right)$ situation, all of which are characterized as prisoner's dilemmas (see Table 1 for the game type of each AS). The two other relevant situations are energy allocation $\left(\mathrm{AS}_{\text {eal }}\right.$, coordination problem) and infrastructure investment $\left(\mathrm{AS}_{\mathrm{inn}}\right.$, prisoner's dilemma). Farmers participate in all situations. The infrastructure maintenance and investment situations $\left(\mathrm{AS}_{\text {imnt }}\right.$ and $\left.\mathrm{AS}_{\text {iinv }}\right)$ also involve governmental actors (i.e., political elites). The following descriptions provide the details for each AS in the RAA project case.

AS $_{\text {wap }}$ : Deciding what to crop at the beginning of the irrigation campaign This situation involves the decisions that farmers have to make at the beginning of the irrigation campaign regarding which crops to grow and on how much of their land. This is indirectly a decision about how much water to withdraw from the system during the irrigation campaign, and it involves an asymmetric social dilemma. All else being equal, profitability is expected to grow with the extension 
of land cropped and with the land devoted to growing high-water-demand crops, such as alfalfa or corn; however, so is water demand, and the risk that water supplied through the irrigation system is lower than demand, particularly if a large number of farmers decide to intensify cropping or if there is a drought. In such a context of water deficit, some crops suffer, thereby resulting in suboptimal production at the collective level regardless of how the water is allocated. The asymmetry results from downstream users' dependence on the behavior of upstream users (Ostrom et al. 1994).

Relevant linkages between water appropriation and allocation are physical: Different acreages and types of crops cultivated determine the water allocation needs, and allocation performance shapes the amount and type of crops that are grown effectively. The equilibrium in this situation has been reached by means of rules that govern the relationship between water allocation $\left(\mathrm{AS}_{\mathrm{wal}}\right)$ and infrastructure maintenance $\left(\mathrm{AS}_{\mathrm{imnt}}\right)$.

\section{$\mathrm{AS}_{\text {imnt }}$ : Maintaining shared infrastructure}

Currently, the irrigation systems rely on a series of reservoirs located in the Gallego and Cinca basins for a total storage capacity of around $930 \mathrm{Hm}^{3}$, as well as on water conveyance and drainage networks of $223 \mathrm{~km}$ each. This impressive infrastructure allows water to be brought in from the Pyrenees mountain range, which is located at the north of the system, through the systems. This is the main source of irrigation water, as precipitation in the area is limited to roughly $350 \mathrm{~mm}$ (VicenteSerrano and Cuadrat-Prats 2007). The maintenance of such infrastructure should not be taken for granted. The benefits of using it are shared by default (i.e., difficult to make exclusive), but the costs are private, inducing incentives to free ride.

Maintenance decisions have a physical influence on water allocation if only because better-maintained infrastructure should allow for better water flow, all else being equal. In addition, there is a rule linking both situations, according to which water allocation to farmers is conditional on their compliance with infrastructure maintenance duties. These duties are carried out in the form of shared labor at the plot level and maintenance fees that are paid to the WUAs and the Water Agency.

\section{$\mathrm{AS}_{\text {mon }}$ : Monitoring compliance}

The existence of rules for water allocation and infrastructure maintenance is associated with a monitoring situation. Monitoring entails costs for those who carry it out, but the benefits are shared in the form of efficient water allocation and the conditions of the infrastructure. There is, indeed, the risk that some free ride on the monitoring effort of others, whether this takes the form of direct patrolling, complaints, or the payment of fees to employ guards. In the RAA project, 
monitoring is performed for the most part by guards whose positions, authority, and protocols are governed by more or less formal rules. This is represented in Fig. 2 as the institutional linkage from monitoring to the water allocation situation. In addition, there is an institutional linkage in the opposite direction. Water is generally allocated according to a turn rule, which permits farmers to easily monitor and quickly identify the origin of disruptions in the water allocation process.

\section{$\mathrm{AS}_{\text {eal }}$ : Allocating energy}

The recent promotion of sprinkler irrigation has resulted in the need to adjust schedules, as sprinklers require more frequent but less intensive irrigation turns than flood irrigation. More critically, the technology transition has resulted in dependence on energy to pump water into the new systems. This is represented in Fig. 2 as a physical linkage. The linkage would not be relevant if it were not for the recent liberalization of Spain's energy sector. This liberalization has been accompanied by an increase in price volatility, as well as a new tariff system that varies depending on the season, day of the week, and hours of the day. This has resulted in the opportunity for farmers to coordinate to minimize energy costs that is, by irrigating only during the low-price periods. The challenge is closer to a coordination problem than to a prisoner's dilemma. Electricity costs are charged to each farmer, depending on the use of sprinkler irrigation and the amount of water withdrawn. Thus, the benefits of adjusting the irrigation schedule would be private (i.e., avoiding individual costs). That said, farmers still need to coordinate via a new irrigation schedule that satisfies all their needs during the low-energy price periods. This is represented in Fig. 2 as an institutional linkage.

$\mathbf{A S}_{\text {iinv }}$ : Infrastructure investments: From hydraulic works to new irrigation technologies

The construction of the RAA should not be taken for granted. The history of irrigation in the area is full of failed attempts by private corporations to provide the necessary infrastructure (Bolea Foradada 1986). This illustrates the profound collective action problem at stake. In an impoverished rural area, funding such infrastructure required cooperation among a vast number of potential beneficiaries from the beginning, which involved considerable transaction costs. At the beginning of the 20th century, after the failure of several private corporations to carry the enterprise, the state took over the initiative. By means of a series of laws, the state funded and built the infrastructure and set a system of use tariffs to be paid by the associations' irrigators who were benefiting from its use. More recently, strong subsidy programs have replaced investments in storage and conveyance infrastructure. The state now supports improvements and the introduction of efficient, pressurized irrigation technologies, such as sprinklers. 
The intervention of the state in the investment situation, both in terms of "infrastructure construction" and "irrigation technology," can be associated with the dynamics of a game that is played among competing political elites who are aiming to gain the electoral favor of the farming lobby. At the beginning of the 20th century, the former colonial empire and economy were in decadence. Irrigated agriculture was then targeted by the political elites as a way to revamp the country's economy. The important weight of the farming sector in the country made the enterprise of building dams and major irrigation canals an activity that governments used to gain political legitimacy throughout most of the century, both before and during Franco's dictatorship (Perez Picazo and Lemeunier 2000). This required the effective coordination and division of labor between the government's departments of public works and agriculture; the former was dominated by public works engineers and the latter by agricultural engineers. With the transition to democracy and the decentralization process in the 1980s, a number of regional political parties took over the irrigation development discourse and policy in an attempt to gain political credit vis-à-vis the central government. Coordination in the form of an assurance game played between regional and central governments was required to avoid a duplication of efforts, and guarantee that both governments could gain political legitimacy through the agricultural investments policy. With the participation in the European Common Agricultural Policy, a number of investments devoted to hydraulic infrastructure decreased and were replaced by the above-mentioned "modernization" programs; however, the stakes of promoting investments have remained the same.

Finally, it is important to mention the coordination game that is played between the political elites and the farmers in the context of infrastructure investments. Both groups have stakes in the aforementioned investments, but both require the participation of the other for the investments to be worthwhile economically and politically. This implicits coalition between the political elites and the farming sector has proved to be particularly resilient since the beginning of the 20th century under the so-called hydro-agricultural policy community (Perez Picazo and Lemeunier 2000).

In terms of linkages, there is an obvious physical connection with water appropriation, as better storage and conveyance infrastructure, as well as more water-efficient technologies, determine the amount of the crops that can be grown.

\subsubsection{Coping with droughts: Insights about centrality and necessity}

In a drought situation, the reduced water availability jeopardizes the equilibrium between farmers' crop water needs and the water that they can effectively use. By default, this means a switch to a suboptimal equilibrium in the cropping situation 
$\left(\mathrm{AS}_{\mathrm{wap}}\right)$; farmers have higher water needs than can be satisfied, and the uncertainty about who grows and what increases (Blanco et al. 2015; Osés-Eraso et al. 2008). This, in turn, jeopardizes the ability of farmers to coordinate water allocation efficiently, because downstream farmers do not know what to expect from upstream farmers.

The main pathway taken to cope with droughts in the RAA project is represented by configuration 1 in Table 1 . This configuration includes a self-imposed quota policy by farmers $\left(\mathrm{AS}_{\mathrm{wap}}\right)$; the strengthening of monitoring $\left(\mathrm{AS}_{\mathrm{mon}}\right)$, over water appropriation; and a reduction in the fees that farmers pay to maintain the irrigation infrastructure $\left(\mathrm{AS}_{\text {imnt }}\right)$. The WUAs have no legal authority over farmers' cropping decisions (Bolea Foradada 1986); however, they have authority over water allocation, and this grants them, via the quotas, indirect agency over the cropping situation. The quotas grant farmers a water allowance for the entire irrigation campaign, depending on the water stored in the reservoirs and the estimations of snow melt. The quota is allocated on an $\mathrm{m}^{3}$-per-hectare basis and enables farmers to adjust their cropping plan accordingly. This is represented in Fig. 2 as an institutional linkage from water allocation to the cropping situation. The quota policy requires that farmers switch crops or reduce the cultivated acreage. The costs of switching crops for many farmers are high (VillamayorTomas 2014); thus, they may prefer violating water allocation rules over facing those costs. To avoid this, the GCRAA and the WUAs intensify patrolling and keep track of the water used by each farmer (see dashed arrows from $\mathrm{AS}_{\text {mon }}$ to $\mathrm{AS}_{\text {wap }}$ and $\mathrm{AS}_{\text {wal }}$ in Fig. 2). The strengthening of monitoring represents the ability of the GCRAA to solve a second-order prisoner's dilemma problem, as monitoring benefits every farmer in the system without distinction but it is costly to provide. Failing to solve that problem would jeopardize compliance by farmers with the quota system (see configuration 1.2 in Table 1). As compensation for the reduced yields, the water agency subsidizes part of the yearly maintenance fees that farmers have to pay (see dashed arrow from the $\mathrm{AS}_{\mathrm{mnt}}$ to $\mathrm{AS}_{\mathrm{wal}}$ in Fig. 2). Again, failing to do so would jeopardize the ability of farmers to pay the fees, initiating a spiral of infrastructure maintenance and fee payment compliance issues. If farmers defect from paying their maintenance fees, others may retaliate by violating water allocation rules. Also, infrastructure leakages will likely affect water flows and allocation everything else being equal. That said the effects of all this may emerge only in the long term (see Table 1, configuration 1.3).

Table 1 includes a second pathway, which consists of the promotion by the government of infrastructure improvements $\left(\mathrm{AS}_{\text {iinv }}\right)$ to increase water efficiency use. In theory, such a measure has the benefit of reducing water needs without putting a burden on farmers' production (see Table 1, configuration 2.1). The reality, however, is different due to the well-known rebound effects (Lecina et al. 2010). 
Encouraged by government's subsidies, farmers have heavily invested in costly sprinkler irrigation technologies and have now to recover the costs by producing more (see Table 1, configuration 2.2). Also, farmers are now more vulnerable to energy market price increases as many of them need electricity to pump the water in to the sprinkler systems.

The notable increase in energy prices in the last years has indeed put farmers in this and other Spanish irrigation systems in a difficult financial situation but has not necessarily undermined their ability to cope with droughts everything else being equal (Cabrera et al. 2010; Dumont et al. 2013) (see Table 1, configuration 2.3).

Overall, the centrality of the water allocation situation, which is connected to the water appropriation, monitoring and maintenance situations, allows us to understand the importance that the quota policy is complemented with strengthened monitoring and partially also with subsidized maintenance during droughts. Indeed, as the above exploration of configurations illustrates, solving the dilemma or coordination problem in at least the water appropriation and monitoring situations would be necessary to maintain a high equilibrium during droughts in the project. By the same token, solving dilemmas/coordination problems in the appropriation situation would be necessary if the efficiency improvements pathway is to be effective. That would not be the case of the energy allocation situation.

\subsection{The electricity-irrigation nexus in Andhra Pradesh: How to enable the transition to a higher equilibrium}

A key challenge in the energy-water nexus is deploying energy-efficient irrigation. In India, agricultural irrigation accounts for more than one fifth of all electric energy end use. In the states of Andhra Pradesh, this share reaches one third. The diffusion of groundwater-based irrigation, accelerated by electricity subsidization, has decisively contributed to the Green Revolution (Badiani et al. 2012; Kondepati 2011), but also led to highly inefficient energy utilization. The policy led to a steady deterioration of electric infrastructure quality. Although state-owned distribution companies were partly compensated by the state for the subsidized agricultural electricity, they steadily reduced investments, maintenance, and staff budgets for rural distribution. This resulted in reduced monitoring capacities and grid maintenance, and it contributed to high voltage fluctuations, poor power quality, and increasing pump set and electricity transformer burnout rates. Nonstandardized, unbranded, and often locally manufactured substandard pump sets, in combination with unqualified repairs, increasing energy inefficiency and further deterioration of power quality.

Analyses of the potential of demand-side management (DSM) in Indian irrigation reveal that comprehensive electricity-side motor improvements and water-side tube 
improvements can increase energy efficiency by up to 50\% (Sant and Dixit 1996). Quality-approved pumps, standardized by the Indian standardization institute ISI, as well as BEE motors rated by the Bureau of Energy Efficiency, could decisively contribute to efficient use. The use of solely a capacitor, which is a small and inexpensive technical device that can balance out voltage and current to improve the power factor in a three-phase electricity supply, can improve energy efficiency by around $10 \%$ and reduce damage to pump sets and transformers. Farmers currently pay INR 6,000 per year for motor and transformer repair, constituting an equivalent of one third of the expenditure on fertilizers and pesticides (Kimmich 2013b). The Andhra Pradesh Electricity Regulatory Commission realized the importance of DSM for increasing energy efficiency and set regulations to force DSM adoption in 2002. However, these rules diverge significantly from practice, as the status of DSM implementation reveals. Why has this electricity-irrigation conundrum remained so persistent, although the improvements could benefit every involved actor? Which situations' outcomes are necessary to trigger equilibrium shifts in the focal AS? Are these situations central?

\subsubsection{The adjacent situations in Andhra Pradesh}

The analysis of a set of heterogeneous ASs can reveal why the existing low equilibrium of poor power quality, inefficient energy use, and constant motor damages is so persistent. The set of adjacent ASs that establishes the low equilibrium (see Fig. 3) comprises a political economic problem of party competition, with parties promising subsidized electricity to win elections $\left(\mathrm{AS}_{\mathrm{pes}}\right)$; a coordination problem to improve power quality in the focal AS, because only simultaneous investments into DSM can improve power quality and efficiency $\left(\mathrm{AS}_{\mathrm{cop}}\right)$; a sequential social learning and technology adoption heuristic $\left(\mathrm{AS}_{\text {slta }}\right)$, which works against simultaneous investments that are necessary to achieve a positive outcome in AScop a common-pool dilemma of infrastructure capacity appropriation or utilization $\left(\mathrm{AS}_{\mathrm{cut}}\right)$, because every additional running motor subtracts from the available capacity; a dilemma of electric infrastructure capacity provision $\left(\mathrm{AS}_{\mathrm{cap}}\right)$; a problem of coordinated collusion between farmers and utility staff $\left(\mathrm{AS}_{\mathrm{col}}\right)$; and a groundwater exploitation dilemma $\left(\mathrm{AS}_{\text {gex }}\right.$ ) (see Fig. 3 and Table 2). The following analyses of ASs capture the dynamics of this low equilibrium trap and the linkages to adjacent situations.

\section{AS $_{\text {pes: }}$ : The political economy of subsidization}

This AS can be depicted as follows: In the late 1970s, new state-level opposition parties $(O)$ emerged that could compete with the Congress party that constituted the incumbent government $(G)$. Electricity subsidization for agriculture became a 
core issue because a large share of the votes could be gained through such a policy. The policy was easy to implement through cross-subsidization and was credible because utilities are state owned, the regulatory agency is dependent, and the distribution of the benefit was easy through the existing electricity grid. This game of party competition has been repeated several times, and the subsidization equilibrium has persisted until today. An analysis of this political economy of electricity provision for irrigation indicates that the subsidization scheme is very likely to persist (Kimmich 2016; Shah et al. 2012). Even a World Bank measure of regulatory reform could not change the policy (World Bank 2001), and farmers resist tariff changes as long as power quality remains poor.

The subsidization policy creates a tariff rule, which shapes the costs and, thus, the incentives to invest in DSM. In Andhra Pradesh, a flat-rate tariff removes any incentive for efficiency improvements. In the opposite direction, the coordination failure in the focal situation of technology coordination $\left(\mathrm{AS}_{\mathrm{cop}}\right)$ leads to poor power quality. Poor service creates an aversion among farmers to pay for electricity provision.

$\mathbf{A S}_{\mathrm{cop}}$ : The coordination problem of power quality improvements

The answer to the surprisingly low adoption of DSM can be found in the characteristics of the electricity infrastructure. The electricity grid creates interdependence between the adoption strategies of the farmers through the network structure and the common-pool resource properties of power quality. Because the use of a poor-quality pump set and not using a capacitor have a negative impact on power quality for all other farmers who are located at the same distribution transformer in the electricity grid, the choice of one farmer to invest in DSM is dependent on the choice of every other connected farmer. When no farmer invests in the use of a capacitor or a standardized ("ISI-marked") pump set, the investment by one farmer does not improve the conditions for her nor for the others. Only if a sufficient number of farmers simultaneously invest in DSM does the overall power quality surpass a threshold level at which the positive effects of DSM on pump sets can be observed. This focal AS of the network, which is decisive for power quality and the eventual willingness to pay, is an assurance problem, because there is no freeriding incentive: Not using a capacitor, for example, even negatively affects the farmer's own pump set if every other farmer uses one.

The experience of coordination failure negatively effects technology adoption by others, because of the negative experience with the respective technology. This is an information linkage to the social learning situation. Conversely, successful coordination could provide the information and understanding that could change the social learning strategy. 
$\mathbf{A S}_{\text {slta }}$ : Social learning for technology adoption

Farmers resort to a common practice with the adoption and implementation of new technologies: Only individual farmers experiment with the use of a capacitor, and the neighbors and peer network adapt to their experiences. Because of this, no experience with coordinated use by all farmers has been possible, thereby impeding any beneficial experience. This AS is different from $\mathrm{AS}_{\text {cop }}$ because the peer network is different from the group of farmers who are located at the same distribution transformer. This existing and actual AS exemplifies a social learning strategy, transferred from other technology adoption problems. This adoption strategy is unable to work when faced with a coordination problem, even though successful for many production technologies, such as introducing a new rice variety. Sequential adoption works against simultaneous experimentation. Yet, when the coordination problem becomes resolved in one instance, social learning can potentially catalyze adoption by neighboring farmers if coordination requirements are learned and transmitted.

The social technology adoption strategy provides information that shapes the decisions in $\mathrm{AS}_{\text {cop }}$, and it is thus represented with an information link in Fig. 3.

\section{AS $_{\text {cut }}$ : Infrastructure capacity utilization as an appropriation dilemma}

The adoption of DSM is not only impeded through coordination failure but also through insufficient infrastructure capacity, leading to low voltage and preventing DSM, such as capacitors and standardized pump sets, from working. Only locally assembled, non-standardized pump sets can stand such low-voltage conditions. Low voltage results from too many pump sets being connected to the same transformer. There is, then, a social dilemma resulting from the overuse of the existing capacity or from infrastructure under-provision. The conflict emerges only if the maximum capacity of the infrastructure is surpassed, in which case the provision of sufficient capacity for every additional connection becomes necessary.

This situation is located at the center of the AS network. The dilemma impedes the coordination of technology adoption but is also physically affected by coordination failure, because inefficient technology requires more capacity. Capacity provision is institutionally linked to the authorization process via the distribution utilities $\left(\mathrm{AS}_{\mathrm{cap}}\right)$, as well as collusion or corruption networks $\left(\mathrm{AS}_{\mathrm{col}}\right)$.

\section{$\mathbf{A S}_{\mathrm{col}}$ : Collusion between farmers and utility: A coordination strategy}

Infrastructure provision is managed by a distribution utility, which requires a connection authorization charge to be paid by every farmer who utilizes power. This charge regularizes the connection and covers costs required for the provision of additional transformer capacity. The authorization process is influenced by many informal arrangements at the substation level. The capacity dilemma is only 
possible because some farmers can evade paying for their connection by colluding with the substation personnel at the electricity distribution company. This collusion, which results from a social network of mutual exchange of favors, is established through multiple games of coordination.

Institutionally, collusion affects the capacity dilemma, enabling free riding, but it is also limited physically if the lowest level of available capacity is reached. Then, the utility can no longer provide capacity for free.

\section{$\mathbf{A S}_{\text {cap }}$ : Infrastructure capacity provision: A dilemma}

The procedure of infrastructure capacity provision becomes subject to this social collusion network. Farmers may evade paying their one-time connection authorization fee and still add additional load, but the utility does not add sufficient transformer capacity to cover this load. This provision game is further complicated by the fact that the utility often delays the authorization and provision of adequate capacity. Similarly, when a transformer is burned out, the utility often delays its repair due to insufficient ground staff.

The utility and colluding farmers' incentive to defect creates the institutions that shape the capacity utilization dilemma $\left(\mathrm{AS}_{\mathrm{cut}}\right)$. The defection in the capacity dilemma, leading to capacity overuse, also corrodes the norm to obey the formal authorization process.

\section{$\mathbf{A S}_{\text {gex }}$ : The dilemma of groundwater exploitation}

In addition to the electricity side, the governance of groundwater itself poses a dilemma. Due to increasing groundwater exploitation, the groundwater table decreases, and farmers have to invest in new bore wells to access the decreasing water tables and deeper aquifers. This results in a competitive process of overexploitation, but the deeper wells also require higher pumping capacity. Higher pumping capacity, in turn, requires sufficient transformer capacity to cope with the increasing load. The dilemma of groundwater abstraction is, thus, intricately linked with the dilemma of infrastructure capacity appropriation and provision. The link is physical. The AS is also affected by the capacity dilemma $\left(\mathrm{AS}_{\text {cut }}\right)$ because limited capacity prevents farmers from increasing the depth of water pumping.

\subsubsection{Centrality and configurations in the network}

From the inspection of the AS network depicted in Fig. 3, the first result concerning centrality becomes obvious: The capacity dilemma $\left(\mathrm{AS}_{\mathrm{cut}}\right)$ has both physical and institutional linkages to four other ASs and is, thus, in terms of the number of ASs it is linked to, the most central AS (see Table 2). The coordination problem and focal situation with the outcome of interest $\left(\mathrm{AS}_{\mathrm{cop}}\right)$, that could 
improve power quality, thereby reduce pump damages and increase energy efficiency, is connected to three ASs and is the second most central AS. AS col $_{\text {and }}$ $\mathrm{AS}_{\text {cap }}$ have equal levels of centrality, while the level of centrality is lowest for $\mathrm{AS}_{\text {pes }}, \mathrm{AS}_{\text {slta }}$, and $\mathrm{AS}_{\text {gex }}$. Thus, changes to the capacity dilemma have an effect on all other situations, except the subsidization policy, with potential spillover effects. A resolved dilemma can, for example, lead to increased groundwater exploitation. Unlike in the Spanish case, the focal situation is not the most central.

A quantitative assessment of the feasibility of multiple equilibria (game type) and the impact on the focal AS (see Kimmich and Sagebiel 2016) reveal the following necessary conditions: The central $\mathrm{AS}_{\text {cut }}$ is a dilemma with a dominant low equilibrium of defection, with the low equilibrium leading to low voltage, thereby reducing the likelihood of farmers being able to coordinate on DSM investments in $\mathrm{AS}_{\text {cop }}$. This is because DSM investments require sufficient voltage levels to work properly. This dilemma is unlikely to be resolved by farmers without changing interactions with the utility staff $\left(\mathrm{AS}_{\mathrm{col}}\right.$ and $\left.\mathrm{AS}_{\text {cap }}\right)$. Clear rules of provision and norms against collusion could lead to adequate authorization and capacity provision by the utility and thereby reduce capacity constraints, resolving the dilemma, and thereby providing the ground for an equilibrium shift in the focal $\mathrm{AS}_{\text {cop }}$. Currently, $\mathrm{AS}_{\mathrm{col}}$ and $\mathrm{AS}_{\text {cap }}$ enable unauthorized connections, and both lead to an asymmetric dilemma in $\mathrm{AS}_{\text {cut }}$, because some farmers are able to collude with the utility staff. $\mathrm{AS}_{\text {col }}$ and $\mathrm{AS}_{\text {cap }}$ cannot change the fact that $\mathrm{AS}_{\text {cut }}$ remains a dilemma in terms of physical payoffs but could potentially change the payoff rules. However, collusion and authorization procedures adhere to persistent norms that are unlikely to change. Both situations' positive outcomes are, however, necessary if groundwater is overexploited and infrastructure capacity therefore overused (see configuration 1 in Table 2). Nevertheless, unlike the larger political economy, they are susceptible to local collective action. The political economy $\left(\mathrm{AS}_{\mathrm{pes}}\right)$ has been persistent despite regulatory changes (Henisz and Zelner 2006; Kimmich 2016; Shah et al. 2012).

In addition, $\mathrm{AS}_{\text {slta }}$ is critical because learning to coordinate on technology adoption would be necessary, albeit not sufficient, for an equilibrium shift in $\mathrm{AS}_{\text {cop }}$. Currently, the focal situation is not perceived as a coordination problem, and farmers stick to sequential social learning institutions and adoption heuristics successful with other technologies, with farmers adopting only if first movers were successful. The overexploitation of groundwater $\left(\mathrm{AS}_{\text {gex }}\right)$ can exacerbate the capacity dilemma $\left(\mathrm{AS}_{\mathrm{cut}}\right)$ and, thus, indirectly prevent successful coordination $\left(\mathrm{AS}_{\mathrm{cop}}\right)$, because low groundwater tables require higher motor loads to pump up water, which lead to voltage fluctuations that prevent DSM from working. When the dilemma occurs, decreasing groundwater tables require higher loads on the 
electricity grid to pump the water upward. This has a negative effect on the capacity dilemma $\left(\mathrm{AS}_{\text {cut }}\right)$, but installing additional capacity could mitigate this problem. Furthermore, overexploitation does not occur in all areas that have been studied.

This differentiation contributes to finding the minimal configurations of ASs to induce change, described in Table 2. Inducing change could be possible by focusing on social learning $\left(\mathrm{AS}_{\text {slta }}\right)$ in the areas in which capacity provision $\left(\mathrm{AS}_{\text {cap }}\right)$ and utilization $\left(\mathrm{AS}_{\mathrm{cut}}\right)$ are sufficient for the level of groundwater exploitation $\left(\mathrm{AS}_{\text {gex }}\right)$, and, thus, the coordination failure in $\mathrm{AS}_{\text {cop }}$ could be more easily overcome (configuration 1). Otherwise, overcoming groundwater exploitation would be a precondition to solve the problems on the electricity side (configuration 2). The farmers could also constrain themselves by reducing electric load on the grid, utilizing only the electric capacity that is available. Then, by solving the coordination problem for DSM investment, the available capacity could be used more efficiently. This configuration 3 most closely resembles self-governance of common-pool resources. If the political economy of subsidization gets resolved and energy is priced according to quantities used, as in configuration 4, farmers still need to coordinate on quality-improving DSM measures to improve outcomes in the focal AS, which entails a resolved capacity dilemma $\left(\mathrm{AS}_{\text {cut }}\right)$.

The economic efficiency of solving coordinated technology adoption ( $\left.\mathrm{AS}_{\mathrm{cop}}\right)$ is very high because of the low costs of related DSM technologies and of inducing a coordinated strategy. The costs of providing additional capacity in $\mathrm{AS}_{\text {cut }}$ first are considerably higher. This would still be necessary in areas of insufficient capacity, but could be facilitated by farmers' updated expectations when observing successful cases, realizing the potentially higher payoffs. The costs of changing $\mathrm{AS}_{\text {gex }}$ cannot be fully estimated, as several additional ASs on the groundwater side would have to be considered. This would require an extension of the boundaries, including groundwater recharge, the provision and maintenance of percolation tanks, or a cropping decision, as in the Spanish case $\left(\mathrm{AS}_{\mathrm{wap}}\right)$. $\mathrm{AS}_{\text {gex }}$ could also become prohibitive with decreasing groundwater tables and may then require the identification of additional ASs on the groundwater side. There is also a caveat with regard to solving $\mathrm{AS}_{\mathrm{cop}}$. Successful technology adoption makes irrigation not only energy-efficient, but also more effective, leading to potentially more extensive groundwater extraction and exploitation. Under the empirically supported hypothesis that improves power quality may lead to the acceptance of electricity tariffs (Dossani and Ranganathan 2004); however, this could ultimately limit water use and induce efficient water use. Technologies and regulations could provide synergies to overcome potential rebound effects. This approach has been tested in the field (Sagebiel et al. 2016). 


\section{Discussion}

The analysis of centrality and configurations offers insights into the logics of change and stability in AS networks. The Spanish case resembles a rather successful system that is robust against droughts, and the analysis points to situations, the governance of which explains such robustness. In the Indian case, the analysis explores potential interventions in order to trigger equilibrium shifts to escape from a low-equilibrium trap and, thus, induce effective change.

In both cases, we find that central ASs are particularly relevant to understanding the feasibility of and dynamics associated to changes in institutions and outcomes. In the Indian case, the most central AS (i.e., capacity utilization) is not the most appropriate situation for efficient policy intervention; the situation partially explains the failure to implement DSM for increasing energy efficiency, but its dependence on both the collusive practices for infrastructure provision and underground water use dynamics questions the costs of an intervention (e.g., measures aiming to increase infrastructure capacity) and its impact on technology adoption. Still, after several unsuccessful DSM policies, which did not take into account coordination requirements, several states are now pursuing a strategy of increasing capacity. In the Spanish case, the focal situation (i.e., water allocation) happens to be the most central; thus, any changes that aim to protect it from the impact of disturbances are to be taken with caution due to potential spillover effects. Indeed, as the case illustrates, drought robustness of the irrigation system is explained with regard to the ability of the system to balance water supply and demand via a quota policy, as well as to the measures taken to counterbalance the spillover effects of the policy on the maintenance situation.

We cannot generalize from our analysis which game types are more or less relevant to achieve the desired equilibria. In the Spanish case, drought robustness is to a great extent facilitated by a policy that reshapes incentives in the cropping $\left(\mathrm{AS}_{\text {wap }}\right)$ situation, which is a dilemma; in the Indian case, a shift to a higher equilibrium is associated with the promotion of coordination in the technology adoption situation $\left(\mathrm{AS}_{\mathrm{cop}}\right)$, which can be self-enforcing, if established. As further discussed below, the relevance of the games actors play is mainly related to whether achieving cooperation in those games makes a difference (i.e., is necessary) to accomplish the desired outcomes in the focal AS.

A key insight resulted from the analysis of interactions across ASs. Some ASs and related outcomes were found to be necessary only within specific AS configurations that led to desired outcomes in the focal AS. When introducing a quota system, as exemplified by the Spanish case, an optimal equilibrium in monitoring AS becomes necessary to enforce the system, but would be ineffective and 
therefore insufficient otherwise. In the Indian electricity-irrigation nexus, adequate capacity provision is necessary, but insufficient to enable coordinated technology adoption. Conversely, knowing how to coordinate technology adoption is insufficient if infrastructure capacity is inadequate to effectively use DSM technologies.

Another insight concerns agency of actors to change behavior. Brown and Westaway (2011) define agency as the ability and capability to act freely, which depends on the structures of the social and physical environment in which the actor is embedded. This is well illustrated in the cases. The Indian case demonstrates that the agency of the farmers to escape the equilibrium trap can be quite high if the respective capabilities to deal with the electricity infrastructure are acquired. The electric utilities, despite being affected by the deteriorating infrastructure, can hardly change the low equilibrium outcome alone given the pumps used by farmers and therefore needs to involve farmers. In the Spanish case, public authorities have agency over situations that are not particularly relevant to cope with droughts; they can modulate fee payments during droughts and also subsidize infrastructure investments, but these measures have little to counteract the lack of water (at least in the short term). Finally, the limited authority of WUAs to tell farmers what to grow is compensated by their agency over the water allocation and their ability to set caps on the amount of water farmers can use during droughts.

The cases also illustrate the importance of network boundaries, i.e., whether the network includes all relevant situations for policy diagnosis. The assessment of the ground water situation in the in Indian case is limited because the network does not include water-related situations such as the provision and maintenance of percolation tanks. Alternatively, the split of the water appropriation situation into a cropping AS and a water allocation AS is useful to understand the Spanish case, even if that distinction has not been made in community-based irrigation governance studies (Bardhan 2000; Ostrom 1992). Network boundaries can vary depending on the types of relationships selected (Laumann et al. 1989; Wasserman and Faust 1994). As highlighted by SNA scholars, failure to include one or more of these links and correctly specify the network boundaries entails the risk of the "partial system fallacy" (Doreian and Woodard 1994). Care to prevent a "partial system fallacy" is especially important in AS networks, where we have to consider physical, informational, institutional, and actor links simultaneously.

The analysis of AS networks could be extended to meta-studies comparing multiple cases, which could help to identify archetypes of typical networks. The archetypes approach in sustainability research dates back to UNEP's fourth Global Environmental Outlook (2007) and has recently been applied to large-scale land acquisitions, for example (Oberlack et al. 2016). Structuring networks into archetypes of recurring patterns could help to synthesize diagnostics and formulate 
common policy options for similar network archetypes. In the context of AS networks, archetypes analyses could extend triadic network closure, as has been done for bipartite networks (Lubell et al. 2014). Game-theoretic approaches to formalization of archetypical AS networks could help to understand generative processes and potentials for change (Kimmich 2013a). Finally, the analysis of AS networks could inform research on structural and functional connectivity (Wainwright et al. 2011), especially for modeling social-ecological and technical systems.

\section{Conclusions}

In this paper, we aim to advance the institutional analysis of resource governance situations by looking at the structure and dynamics of the networks they form. Specifically, we use a configurational method to analyze AS networks and we operationalize a measure of centrality to understand the feasibility and dynamics of institutional and equilibrium changes. We observe the types of links and the games actors play in different resource governance situations of the network. Centrality is measured by looking at the physical, institutional, informational, and actor links between ASs. We identify configurations of situations that are necessary (albeit insufficient by their own) to explain desirable network equilibria.

Through an application to two irrigation cases, we find that the assessment of centrality and configurations of "necessary but insufficient" ASs is useful to understanding the mechanisms through which desired outcomes are produced. As a caveat for future work, we need to better study the relationship between necessary situations' outcomes and agency, and further systematize how to identify the relevant boundaries of AS networks.

The cases were not used for comparative purposes. The findings do not allow for general conclusions about water or natural resource governance, but inform about the concepts and methods through which we can assess complex humanenvironmental interactions for policy diagnosis. An extension of the analysis of ASs that allows generalization about natural resource governance could focus on the meta-analysis of networks (i.e., cases) with similar or different structures and composition. Archetypes of typical network configurations could be identified.

More generally, the approach is useful to identify conflicts and synergies between outcomes of different linked ASs in social-ecological and technical systems. In the context of energy-fed irrigation systems, synergies between groundwater governance, infrastructure capacity, and coordinated technology adoption, for example, improve energy efficiency far more effectively than any of those situations could do separately. In drought-exposed irrigation systems, the approach 
allows localizing trade-offs between allocating water efficiently and maintaining other important system functions, such as food production and infrastructure maintenance.

\section{Acknowledgments}

We would like to thank participants of the research colloquium at the Division of Resource Economics at HU Berlin, especially Mario Arauz, Kinga Boening, Ranjan Ghosh, Philipp Grundmann and Shigeo Watanabe for valuable feedback on earlier presentations of this work. We also thank Bryan Bruuns for very detailed comments on an earlier draft, Richard Feiock for his discussion of our paper at the MPSA 2013 in Chicago, Edella Schlager for her valuable suggestions, and participants of the WOW5 at Indiana University Bloomington.

\section{References}

Anderies, JM, MA Janssen and E Ostrom (2004). A framework to analyze the robustness of social-ecological systems from an institutional perspective. Ecology and Society, 9(1). Available at http://www.ecologyandsociety.org/vol9/iss1/art18/.

Badiani, R, KK Jessoe and S Plant (2012). Development and the environment: The implications of agricultural electricity subsidies in India. The Journal of Environment \& Development, 21(2), 244-262. doi: 10.1177/1070496512442507.

Bardhan, P (2000). Irrigation and cooperation: An empirical analysis of 48 irrigation communities in South India. Economic Development and Cultural Change, 48(4), 847-865.

Blanco, E, MC Lopez and S Villamayor-Tomas (2015). Exogenous degradation in the commons: Field experimental evidence. Ecological Economics, doi:http://dx.doi.org/ 10.1016/j.ecolecon.2015.03.028.

Blomquist, W and E Schlager (2005). Political pitfalls of integrated watershed management. Society \& Natural Resources, 18(2), 101-117. doi: 10.1080/08941920590894435.

Blomqvist, K, P Hurmelinna and R Seppänen (2005). Playing the collaboration game right - balancing trust and contracting. Technovation, 25(5), 497-504. doi: 10.1016/j. technovation.2004.09.001.

Bolea Foradada, JA (1986). Los riegos de Aragon. Huesca, Spain: Grupo Parlamentario Aragones Regionalista de las Cortes de Aragon.

Bowles, S (2004). Microeconomics: Behavior, Institutions, and Evolution. New York, Princeton, N. J.: Russell Sage, Princeton University Press.

Brown, K and E Westaway (2011). Agency, capacity, and resilience to environmental change: Lessons from human development, well-being, and disasters. Annual Review of Environment and Resources, 36(1), 321-342. doi: 10.1146/annurev-environ052610-092905. 
Cabrera, E, MÁ Pardo, E Cabrera Jr and R Cobacho (2010). Agua y energía en España. Un reto complejo y fascinante. Ingeniería del agua, 17(3), 235-246.

Costenbader, E and TW Valente (2003). The stability of centrality measures when networks are sampled. Social Networks, 25(4), 283-307. doi: 10.1016/S0378-8733(03) 00012-1.

Doreian, P and KL Woodard (1994). Defining and locating cores and boundaries of social networks. Social Networks, 16, 267-293. doi:http://dx.doi.org/10.1016/0378-8733 (94)90013-2.

Dossani, R and V Ranganathan (2004). Farmers' willingness to pay for power in India: Conceptual issues, survey results and implications for pricing. Energy Economics, 26(3), 359-369.

Dumont, A, B Mayor and E López-Gunn (2013). Is the rebound effect or Jevons paradox a useful concept for better management of water resources? Insights from the irrigation modernisation process in Spain. Aquatic Procedia, 1, 64-76.

Everett, MG and SP Borgatti (2005). Extending centrality. In Models and Methods in Social Network Analysis, PJ Carrington, J Scot and S Wasserman (eds.), pp. 57-77. Cambridge: Cambridge University Press.

Farrell, J and P Klemperer (2007). Coordination and lock-in: Competition with switching costs and network effets. In M Armstrong and RH Porter (eds.), Handbook of Industrial Organization, Vol. 3, pp. 1970-2072. Amsterdam: North-Holland.

Freeman, LC (1978). Centrality in social networks conceptual clarification. Social Networks, 1, 215-239. doi:http://dx.doi.org/10.1016/0378-8733(78)90021-7.

Galeotti, A, S Goyal, MO Jackson, F Vega-Redondo and L Yariv (2010). Network games. Review of Economic Studies, 77(1), 218-244. doi: 10.1111/j.1467-937X.2009.00570.x.

Hagedorn, K (2008). Particular requirements for institutional analysis in nature-related sectors. European Review of Agricultural Economics, 35, 357-384. doi: 10.1093/ erae/jbn019.

Hamidov, A, A Thiel and D Zikos (2015). Institutional design in transformation: A comparative study of local irrigation governance in Uzbekistan. Environmental Science \& Policy, Part B, 53, 175-191. doi: 10.1016/j.envsci.2015.06.012.

Hassink, J, W Hulsink and J Grin (2012). Care farms in the Netherlands: An underexplored example of multifunctional agriculture - Toward an empirically grounded, organization-theory-based typology. Rural Sociology, 77(4), 569-600. doi: 10.1111/ j.1549-0831.2012.00089.x.

Henisz, WJ and BA Zelner (2006). Interest groups, veto points, and electricity infrastructure deployment. International Organization, 60(1), 263-286. doi: 10.1017/ S0020818306060085.

Kashwan, P (2015). Integrating power in institutional analysis: A micro-foundation perspective. Journal of Theoretical Politics, doi: 10.1177/0951629815586877.

Kimmich, C (2013a). Linking action situations: Coordination, conflicts, and evolution in electricity provision for irrigation in Andhra Pradesh, India. Ecological Economics, 90(0), 150-158. doi: 10.1016/j.ecolecon.2013.03.017.

Kimmich, C (2013b). Incentives for energy-efficient irrigation: Empirical evidence of technology adoption in Andhra Pradesh, India. Energy for Sustainable Development, 17(3), 261-269. doi:http://dx.doi.org/10.1016/j.esd.2013.02.004. 
Kimmich, C (2016). Can analytic narrative inform policy change? The political economy of the Indian electricity-irrigation nexus. The Journal of Development Studies, 52(2), 269-285. doi: 10.1080/00220388.2015.1093119.

Kimmich, C and J Sagebiel (2016). Empowering irrigation: A game-theoretic approach to electricity utilization in Indian agriculture. Utilities Policy, 43B, 174-185. doi: 10.1016/j.jup.2016.10.002.

Kiser, LL and E Ostrom (2000). The three worlds of action: A metatheoretical synthesis of institutional approaches. In MD McGinnis (ed.), Polycentric Games and Institutions: Readings from the Workshop in Political Theory and Policy Analysis, p. xvi, 541 p Ann Arbor: University of Michigan Press.

Kondepati, R (2011). Agricultural groundwater management in Andhra Pradesh, India: A focus on free electricity policy and its reform. International Journal of Water Resources Development, 27(2), 375-386. doi: 10.1080/07900627.2011.564971.

Laumann, EO, PV Marsden and D Prensk (1989). The boundary specification problem in network analysis. In LC Freeman, DR White and A Kimball Rommney (eds.), Research Methods in Social Network Analysis, pp. 61-87. Fairfax, VA: George Mason University Press.

Lecina, S, D Isidoro, E Playán and R Aragüés (2010). Irrigation modernization and water conservation in Spain: The case of Riegos del Alto Aragón. Agricultural Water Management, 97(10), 1663-1675.

Lubell, M (2013). Governing institutional complexity: The ecology of games framework. Policy Studies Journal, 41(3), 537-559. doi: 10.1111/psj.12028.

Lubell, M, G Robins and P Wang (2014). Network structure and institutional complexity in an ecology of water management games. Ecology and Society, 19(4). doi: 10.5751/ ES-06880-190423.

McGinnis, MD (2011). Networks of adjacent action situations in polycentric governance. Policy Studies Journal, 39(1), 51-78. doi: 10.1111/j.1541-0072.2010.00396.x.

Meyer, AD, AS Tsui and CR Hinings (1993). Configurational approaches to organizational analysis. Academy of Management Journal, 36(6), 1175-1195.

Meyer, C and A Thiel (2012). Institutional change in water management collaboration: Implementing the European Water Framework Directive in the German Odra river basin. Water Policy, 14(4), 625-646.

Moss, T (2004). The governance of land use in river basins: Prospects for overcoming problems of institutional interplay with the EU Water Framework Directive. Land Use Policy, 21(1), 85-94. doi: 10.1016/j.landusepol.2003.10.001.

Müller, M, J Rommel and C Kimmich (2016). Farmers' adoption of irrigation technologies: Experimental evidence from a coordination game with positive network externalities in India. German Economic Review. doi: 10.1111/geer.12117.

Oberlack, C, L Tejada, P Messerli, S Rist and M Giger (2016). Sustainable livelihoods in the global land rush? Archetypes of livelihood vulnerability and sustainability potentials. Global Environmental Change, 41, 153-171. doi: 10.1016/j.gloenvcha.2016.10.001.

Osés-Eraso, N, F Udina and M Viladrich-Grau (2008). Environmental versus humaninduced scarcity in the commons: Do they trigger the same response?, Environmental and Resource Economics, 40(4), 529-550. doi: 10.1007/s10640-007-9168-6. 
Ostrom, E (1992). Crafting Institutions for Self-governing Irrigation Systems. San Francisco, Calif.: ICS Press.

Ostrom, E, R Gardner and J Walker (1994). Rules, Games and Common-Pool Resources. Michigan: The University of Michigan Press.

Ostrom, E, LD Schroeder and SG Wynne (1993). Institutional Incentives and Sustainable Development: Infrastructure Policies in Perspective, p. 266. Boulder: Westview Press.

Pahl-Wostl, C, G Holtz, B Kastens and C Knieper (2010). Analyzing complex water governance regimes: The Management and transition framework. Environmental Science \& Policy, 13(7), 571-581. doi:http://dx.doi.org/10.1016/j.envsci.2010.08.006.

Perez Picazo, MT and G Lemeunier (2000). Formation et mise en cause du modèle de gestion hydraulique espagnol de 1780 a 2000. Economies et Socits, 34(2), 73-100.

Ragin, CC (1989). The Comparative Method: Moving Beyond Qualitative and Quantitative Strategies. University of California Press.

Rihoux, B and CC Ragin (2009). Configurational Comparative Methods: Qualitative Comparative Analysis (QCA) and Related Techniques. Sage.

Roggero, M (2015). Adapting institutions: Exploring climate adaptation through institutional economics and set relations. Ecological Economics, 118, 114-122. doi: 10.1016/j.ecolecon.2015.07.022.

Sagebiel, J, C Kimmich, M Müller, M Hanisch and V Gilani (2016). Enhancing Energy Efficiency in Irrigation: A Socio-Technical Approach in South India. Dordrecht: Springer.

Sant, G and S Dixit (1996). Agricultural pumping efficiency in India: The role of standards. Energy for Sustainable Development, 3(1), 29-37.

Schlüter, M, D Hirsch and C Pahl-Wostl (2010). Coping with change: Responses of the Uzbek water management regime to socio-economic transition and global change. Environmental Science \& Policy, 13(7), 620-636. doi:http://dx.doi.org/10.1016/j. envsci.2010.09.001.

Scott, J (2012). Social Network Analysis. Sage.

Sendzimir, J, Z Flachner, C Pahl-Wostl and C Knieper (2010). Stalled regime transition in the upper Tisza River Basin: The dynamics of linked action situations. Environmental Science \& Policy, 13(7), 604-619. doi:http://dx.doi.org/10.1016/j.envsci.2010.09.005.

Shah, T, M Giordano and A Mukherji (2012). Political economy of the energy-groundwater nexus in India: Exploring issues and assessing policy options. Hydrogeology Journal, 20(5), 995-1006. doi: 10.1007/s10040-011-0816-0.

Siddiki, S, CM Weible, X Basurto and J Calanni (2011). Dissecting policy designs: An application of the institutional grammar tool. Policy Studies Journal, 39(1), 79-103. doi: 10.1111/j.1541-0072.2010.00397.x.

Subramanian, A, NV Jagannathan and RS Meinzen-Dick (1997). User Organizations for Sustainable Water Services, Vol. 354. World Bank Publications.

UNEP (2007). Global Environmental Outlook 4. Valetta: Progress Press Ltd.

Vicente-Serrano, SM and JM Cuadrat-Prats (2007). Trends in drought intensity and variability in the middle Ebro valley (NE of the Iberian peninsula) during the second half of the twentieth century. Theoretical and Applied Climatology, 88, 247-258. doi: 10.1007/s00704-006-0236-6. 
Villamayor-Tomas, S (2014). Cooperation in common property regimes under extreme drought conditions: Empirical evidence from the use of pooled transferable quotas in Spanish irrigation systems. Ecological Economics, 107(0), 482-493. doi: 10.1016/j. ecolecon.2014.09.005.

Wainwright, J, L Turnbull, TG Ibrahim, I Lexartza-Artza, SF Thornton and RE Brazier (2011). Linking environmental régimes, space and time: Interpretations of structural and functional connectivity. Geomorphology on Multiscale Feedbacks in Ecogeomorphology, 126(3-4), 387-404. doi: 10.1016/j.geomorph.2010.07.027.

Wasserman, S and K Faust (1994). Social Network Analysis: Methods and Applications. New York: Cambridge University Press.

World Bank (2001). India: Power Supply to Agriculture. Volume 1: Summary Report. World Bank. 